\title{
CRESCIMENTO DE MUDAS DE CLONES DE EUCALIPTO SUBMETIDOS À DERIVA SIMULADA DE DIFERENTES HERBICIDAS ${ }^{1}$
}

\author{
Rafael Augusto Soares Tiburcio ${ }^{2}$, Francisco Affonso Ferreira ${ }^{3}$, Frederico Alfenas Silva Valente Paes ${ }^{4}$, \\ Christiane Augusta Diniz Melo ${ }^{5}$ e Wilker Nunes Medeiros²
}

\begin{abstract}
RESUMO - Entre as possibilidades de manejo de plantas daninhas, o método químico é o mais utilizado. No entanto, um possível problema apresentado por esse método é a deriva acidental. Assim, conhecer esse risco e como quantificar seu efeito na cultura é fundamental para que esses produtos sejam empregados corretamente no manejo de plantas daninhas. Este trabalho teve como objetivo estudar o efeito da deriva simulada de herbicidas, por meio de subdoses, no crescimento de mudas de dois clones de eucalipto, considerando-se a possibilidade de extensão de seu uso. Foram utilizados os herbicidas atrazine, nicossulfuron e tembotrione e as misturas formuladas foramsulfurom + iodossulfurom-metílico e fluazifop-p-butyl + fomesafen, aplicados nas doses correspondentes a 3, 6 e 12\% da dose recomendada. Foi avaliada a porcentagem de intoxicação, altura, diâmetro do caule e massa de matéria seca da parte aérea. Os herbicidas afetaram o crescimento das plantas de eucalipto, limitando principalmente o incremento em massa de matéria seca da parte aérea. O risco de perdas de produtividade, caso haja intoxicação via deriva, é menor com atrazine, foramsulfurom + iodossulfurom-metílico e tembotrione e maior com fluazifop-p-butyl + fomesafen e nicossulfuron. Entre os produtos testados, o tembotrione é o que apresenta maior potencial para ser utilizado em áreas de eucalipto.
\end{abstract}

Palavras-chave: Intoxicação de plantas, Deriva de herbicida e Espécie arbórea.

\section{GROWTH OF EUCALYPTUS CLONES SEEDLINGS SUBMITTED TO SIMULATED DRIFT OF DIFFERENT HERBICIDES}

\begin{abstract}
Among the possibilities of weed management, the chemical method is the most used one. However, a potential problem presented by this method is the accidental drift. Thus, knowledge on the risk and on how to quantify it and its effect on the crop is essential for a correct use of these products in weed management. The objective of this work was to study the effect of simulated herbicide drift through underdosing in the growth of two eucalyptus clones seedlings, considering the possible extension of their use. The herbicides used were atrazine, nicosulfuron and tembotrione, and formulated mixtures were foramsulfurom + iodosulfurom-methyl and fluazifop-p-butyl + fomesafen, applied at doses corresponding to 3, 6 and 12\% of the recommended dose. It was evaluated percentage of intoxication, height, stem diameter and shoot dry mass. Herbicides affected the growth of eucalyptus plants, mainly by limiting increase in shoot dry mass. The risk of productivity loss in case of intoxication if drift occurs is reduced with the use of atrazine, foramsulfurom + iodosulfurom-methyl and tembotrione and it was higher with the use of fluazifop-p-butyl + fomesafen and nicosulfuron. Among the tested products, tembotrione is the one that shows the greatest potential to be used in eucalyptus areas.
\end{abstract}

Keywords: Plant intoxication, Herbicide drift and Tree species.

\footnotetext{
${ }^{1}$ Recebido em 03.12.2010 e aceito para publicação em 15.11.2011.

${ }^{2}$ Programa de Pós-Graduação em Engenharia Agrícola pela Universidade Federal de Viçosa, UFV, Brasil. E-mail: < rafael.tiburcio@ufv.br> e<wilkermedeiros@yahoo.com.br>.

${ }^{3}$ Universidade Federal de Viçosa, UFV, Brasil. E-mail: <faffonso@ufv.br>

${ }^{4}$ Programa de Pós-Graduação em Solos e Nutrição de Plantas, Universidade Federal de Viçosa, UFV, Brasil. E-mail: <fredericoalfenas@gmail.com>.

${ }^{5}$ Programa de Pós-Graduação em Fitotecnia, Universidade Federal de Viçosa, UFV, Brasil. E-mail: <chrisadinizmelo@yahoo.com.br>.
} 


\section{INTRODUÇÃO}

A competitividade do setor florestal brasileiro é crescente, em razão das condições climáticas e das tecnologias desenvolvidas no país. Devido ao crescimento da produção das empresas florestais e das demandas internacionais por produtos da cadeia, o Brasil tornou-se um dos maiores exportadores de produtos florestais (VALVERDE, 2004), destacando nesse cenário a produção de eucalipto.

Um dos fatores que limitam a produtividade do eucalipto são as plantas daninhas, que competem pelos recursos disponíveis no ambiente, afetando o crescimento das plantas, além de dificultar os tratos culturais, aumentando os riscos de incêndios e as operações de colheita. As plantas daninhas estão presentes nos plantios de eucalipto em níveis variáveis de densidade e espécies, competindo, principalmente, por luz, água e nutrientes, e proporcionando perdas significativas de produtividade (COSTAet al., 2004). Além da competição, o eucalipto pode sofrer interferência também de efeitos alelopáticos (SOUZA et al., 2003).

Entre as possibilidades de manejo de plantas daninhas, o método químico é o mais utilizado. Porém, o uso indiscriminado de um mesmo herbicida favorece o aumento de indivíduos tolerantes na área e a seleção de espécies resistentes, podendo diminuir a eficiência dos herbicidas ao longo do tempo. Há poucos herbicidas registrados para a cultura do eucalipto, entre os quais o glyphosate é o mais usado por controlar grande número de espécies. Entretanto, no Brasil já são conhecidas cinco espécies com biótipos resistentes ao glyphosate, sendo elas Conyza bonariensis, Conyza canadensis, Digitaria insularis, Lolium multiflorum e Euphorbia heterophylla (WEED SCIENCE, 2010). Nesse sentido, o registro de novos produtos se faz importante para permitir maior rotação de herbicidas, visando evitar esses problemas.

Uma alternativa para aumentar o número de herbicidas para o eucalipto é a extensão de uso de produtos já registrados para outras culturas. Nesse contexto estão os herbicidas atrazine, foramsulfurom + iodossulfurometílico, nicossulfuron e tembotrione, que são registrados para a cultura do milho, e fluazifopp-butyl + fomesafen, que é registrado para a cultura da soja e do feijão, produtos esses aplicados em pósemergência das plantas daninhas, propiciando controle efetivo sobre ampla gama de espécies daninhas. $O$ atrazine é um herbicida de translocação via xilema e que inibe a atividade do fotossistema II (PRESTON et al., 2001). A mistura formulada fluazifop-p-butyl + fomesafen é formada por dois ingredientes ativos, o fluazifop-pbutyl, herbicida sistêmico que inibe a atividade da enzima Acetil Coenzima A Carboxilase (ACCase) (TILL, 2003), e o fomesafen, herbicida de contato que inibe a atividade da enzima protoporfirinogênio oxidase (PROTOX). A mistura formulada foramsulfurom + iodossulfurometílico e o nicossulfuron são herbicidas de ação sistêmica que inibem a atividade da acetolactato sintase (ALS) (ANDERSON et al., 1998). O tembotrione é um herbicida sistêmico que inibe a biossíntese de carotenoides, inibindo a ação da enzima 4-hidroxifenilpiruvatodioxigenase (FERREIRA et al., 2005).

Quando o herbicida não é seletivo, deve-se aplicá-lo de forma dirigida, apresentando risco de deriva acidental, ou seja, deposição do produto fora do alvo. A deriva é considerada um sério problema em muitas áreas de cultivo de eucalipto (TUFFI SANTOS et al., 2006ab; YAMASHITA et al., 2006). A metodologia mais utilizada para a quantificação da deriva é através da aplicação de subdoses do produto. Vários autores já demonstraram os prejuízos ocasionados pela deriva de herbicidas em eucalipto e culturas anuais (Tuffi Santos et al., 2005; 2006ab; 2007ab; 2009; Alves et al., 2000; Magalhães et al., 2001). Suas causas são muitas e estão relacionadas com os equipamentos de aplicação, as formulações e as condições meteorológicas. Bode (1984) relatou a deposição de produtos devido à deriva entre 5 e $9 \%$ da dose aplicada com equipamentos terrestres, sob condições climáticas ideais para aplicação. Assim, conhecer o risco de deriva e como quantificar seu efeito na planta é fundamental para que esses produtos sejam utilizados no manejo de plantas daninhas.

Diante do exposto, este trabalho teve como objetivo estudar o efeito da deriva simulada por meio de subdoses dos herbicidas atrazine, foramsulfurom + iodossulfurometílico, fluazifop-p-butyl + fomesafen, nicossulfuron e tembotrione no crescimento de mudas de dois clones de eucalipto, considerando-se a possibilidade de extensão de uso desses herbicidas para o eucalipto e, ou, também a possibilidade de uso desses produtos em culturas consorciadas com o eucalipto no sistema de Integração Lavoura, Pecuária e Floresta. 


\section{MATERIAL E MÉTODOS}

O experimento foi realizado em casa de vegetação, utilizando-se mudas padronizadas de dois clones de Eucalyptus grandis x E. urophylla com três meses de idade, cedidas pela Empresa Cenibra e codificadas como 386 e 2719. Essas mudas foram transplantadas para vasos de $10 \mathrm{~L}$, previamente preenchidos com solo argiloso e adubados, conforme recomendação. As plantas de eucalipto receberam irrigação por microaspersão diariamente, de modo que mantivessem adequada disponibilidade de água.

Foram utilizados os herbicidas atrazine, foramsulfurom + iodossulfurom-metílico, fluazifop-pbutyl + fomesafen, nicossulfuron e tembotrione, aplicados nas doses correspondentes a 3, 6 e 12\% da dose recomendada para cada produto (Tabela 1 ).

A aplicação foi realizada diretamente sobre as mudas, de modo que não atingisse o seu terço superior, 25 dias após o transplantio, quando essas mudas apresentavam cerca de $45 \mathrm{~cm}$ de altura. Utilizou-se um pulverizador costal de precisão, munido de barra com dois bicos com pontas tipo leque TT11002, espaçados $0,5 \mathrm{~m}$, operando a $300 \mathrm{kPa}$, com volume de calda de $150 \mathrm{~L} \mathrm{ha}^{-1}$. No momento da aplicação, a umidade relativa do ar, a temperatura e a velocidade média do vento eram de $65 \pm 2 \%, 22,5 \pm 1{ }^{\circ} \mathrm{Ce} 3,2 \mathrm{~km} \mathrm{~h}^{-1}$, respectivamente. Após a aplicação, as plantas permaneceram $24 \mathrm{~h}$ sem o contato com água da chuva ou da irrigação, visando evitar a lavagem das folhas.
Aos 7, 15 e 30 dias após a aplicação (DAA), avaliou-se a porcentagem de intoxicação em relação à testemunha, em que $0 \%$ correspondeu à ausência de sintomas visíveis e $100 \%$ à morte das plantas (FRANS, 1972). Foram mensurados a altura (região entre o coleto e o ápice) e o diâmetro do caule a $5 \mathrm{~cm}$ do solo de todas as plantas, 1e 50 DAA. Subtraindo a altura e o diâmetro nesse intervalo de tempo, obteve-se a variação dessas características avaliadas para cada planta. Aos 51 DAA foi coletada a parte aérea das plantas separadamente (folhas + caule) e acondicionada em sacos de papel colocados em estufa com circulação forçada de ar $\left(65 \pm 3^{\circ} \mathrm{C}\right)$ até atingir massa constante. A massa de matéria seca da parte aérea foi obtida através da soma das massas de matéria seca do caule e das folhas.

Cada tratamento foi analisado independentemente em esquema fatorial 2 x 4 (dois clones e três doses + uma testemunha) no delineamento em blocos casualizados com quatro repetições, sendo a unidade experimental uma planta por vaso.

Os dados de altura, diâmetro de caule e massa seca da parte aérea foram transformados para porcentagem em relação à testemunha. Após serem submetidos aos testes de Cochran (Homocedasticidade) e Lilliefors (normalidade dos dados), os dados foram analisados por meio de análise de variância e de regressão em nível de significância de 5\% de probabilidade. Os modelos ajustados foram escolhidos de acordo com

Tabela 1 - Tratamentos avaliados e as respectivas quantidades de ingrediente ativo e produto comercial por hectare. Table 1 - Treatments evaluated and the respective amounts of active ingredient and commercial product per hectare.

\begin{tabular}{|c|c|c|c|}
\hline \multicolumn{2}{|l|}{ Tratamentos } & \multirow[t]{2}{*}{ Dose(i.a ha-1) } & \multirow[t]{2}{*}{ Dose(p.c ha $\left.{ }^{-1}\right)$} \\
\hline Herbicidas & $\%$ da dose recomendada & & \\
\hline Atrazine ${ }^{1}$ & 3 & $72 \mathrm{~g}$ & $180 \mathrm{~mL}$ \\
\hline Atrazine ${ }^{1}$ & 6 & $144 \mathrm{~g}$ & $360 \mathrm{~mL}$ \\
\hline Atrazine ${ }^{1}$ & 12 & $288 \mathrm{~g}$ & $720 \mathrm{~mL}$ \\
\hline Foramsulfurom + iodosulfurom-metílico ${ }^{2}$ & 3 & $1,35 \mathrm{~g}+0,09 \mathrm{~g}$ & $4,5 \mathrm{~g}$ \\
\hline Foramsulfurom + iodosulfurom-metílico ${ }^{2}$ & 6 & $2,7 g+0,18 g$ & $9,0 \mathrm{~g}$ \\
\hline Foramsulfurom + iodosulfurom-metílico ${ }^{2}$ & 12 & $5,4 \mathrm{~g}+0,36 \mathrm{~g}$ & $18 \mathrm{~g}$ \\
\hline Fluazifop-p-butyl + fomesafen ${ }^{3}$ & 3 & $6 g+7,5 g$ & $30 \mathrm{~mL}$ \\
\hline Fluazifop-p-butyl + fomesafen ${ }^{3}$ & 6 & $12 g+15 g$ & $60 \mathrm{~mL}$ \\
\hline Fluazifop-p-butyl + fomesafen ${ }^{3}$ & 12 & $24 g+30 g$ & $120 \mathrm{~mL}$ \\
\hline Nicosulfuron ${ }^{4}$ & 3 & $1,8 \mathrm{~g}$ & $45 \mathrm{~mL}$ \\
\hline Nicosulfuron ${ }^{4}$ & 6 & $3,6 \mathrm{~g}$ & $90 \mathrm{~mL}$ \\
\hline Nicosulfuron ${ }^{4}$ & 12 & $7,2 \mathrm{~g}$ & $180 \mathrm{~mL}$ \\
\hline Tembotrione ${ }^{5}$ & 3 & $3,02 \mathrm{~g}$ & 7,2 mL \\
\hline Tembotrione ${ }^{5}$ & 6 & $6,04 \mathrm{~g}$ & $14,4 \mathrm{~mL}$ \\
\hline Tembotrione ${ }^{5}$ & 12 & $12,09 \mathrm{~g}$ & $28,8 \mathrm{~mL}$ \\
\hline Testemunha & - & - & -- \\
\hline
\end{tabular}


a significância dos coeficientes de regressão, utilizando-se o teste $\mathrm{t}$ a $5 \%$ de probabilidade, o coeficiente de determinação e o fenômeno biológico.

\section{RESULTADOS}

Na análise de variância da intoxicação de plantas, a interação clone $\mathrm{x}$ dose e o efeito de clones foram não significativos para todos herbicidas testados, utilizando-se, assim, a média dos clones na análise de regressão. A regressão foi significativa apenas para fluazifop-p-butyl + fomesafen e nicossulfuron (Figura 1).

Os sintomas de intoxicação foram caracterizados por pequenas cloroses foliares até os 15 DAA nas plantas tratadas com atrazine e até os 7 DAA nas plantas tratadas com foramsulfuron + iodossulfurommetílico. Nessas plantas, a intoxicação não ultrapassou $6 \%$, sendo considerada leve segundo a escala utilizada pela Sociedade Brasileira de Ciência das Plantas Daninhas. Esses herbicidas mostraramse pouco tóxicos às plantas de eucalipto, apesar de provocar alguns sintomas de intoxicação. As plantas tratadas com nicossulfuron apresentaram estreitamento foliar e necrose dos ápices, enquanto as tratadas com a mistura formulada de fluazifop- p-butyl + fomesafen apresentaram apenas necroses. Esses herbicidas causaram as maiores porcentagens de intoxicação. Já para o tembotrione não foram observados sintomas de intoxicação nas plantas tratadas em nenhuma das doses utilizadas.

Na análise de variância da altura, a interação clone x dose foi não significativa em todos os herbicidas testados, e a regressão foi significativa apenas em tembotrione e nicossulfuron. Nesses, o efeito de clones foi significativo no nicossulfuron e não significativo no tembotrione, utilizando-se a média dos clones na regressão (Figura 2).

Em relação ao diâmetro do caule, não houve efeito significativo em clone e na interação clone $\mathrm{x}$ dose em nenhum dos herbicidas testados. A regressão foi significativa para foramsulfuron + iodossulfurom-metílico, fluazifop-p-butyl + fomesafen e nicossulfuron (Figura 3).

Considerando a produção de massa de matéria seca da parte aérea, também não houve efeito de clones e da interação clone $x$ dose. A regressão foi significativa em todos os herbicidas testados (Figura 4), em que se observou que, com o aumento das doses de todos os herbicidas, ocorreu decréscimo no acúmulo de massa de matéria seca da parte aérea.
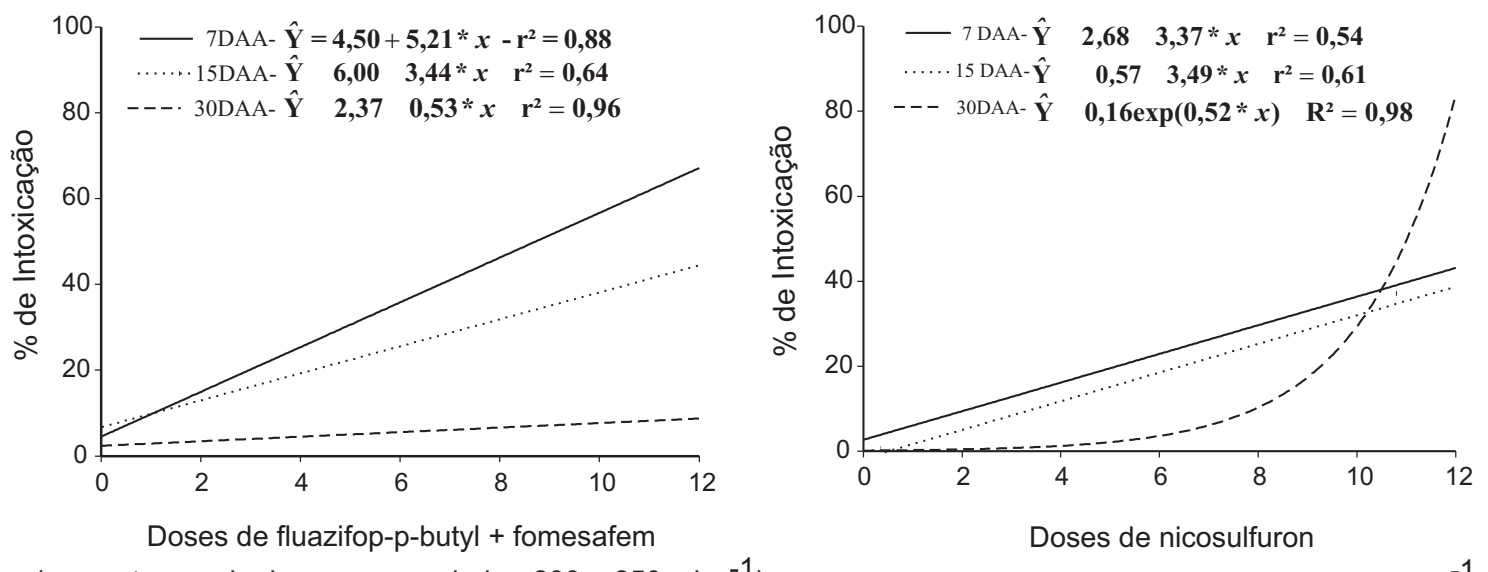

(porcentagem da dose recomendada $-200+250 \mathrm{~g} \mathrm{ha}^{-1}$ ) (porcentagem da dose recomendada - $60 \mathrm{~g} \mathrm{ha}^{-1}$ )

Figura 1 - Porcentagem de intoxicação observada em plantas de eucalipto (média de dois clones) submetidas à deriva simulada dos herbicidas fluazifop-p-butyl + fomesafen e nicossulfuron em diferentes doses, aos 7, 15 e 30 DAA.

Figure 1 - Percentage of intoxication observed of eucalyptus plants (average of two clones) submitted to simulated drift of the herbicides fluazifop-p-butyl + fomesafen and nicosulfuron at different doses, at 7, 15 and $30 D A A$.

Revista Árvore, Viçosa-MG, v.36, n.1, p.65-73, 2012 

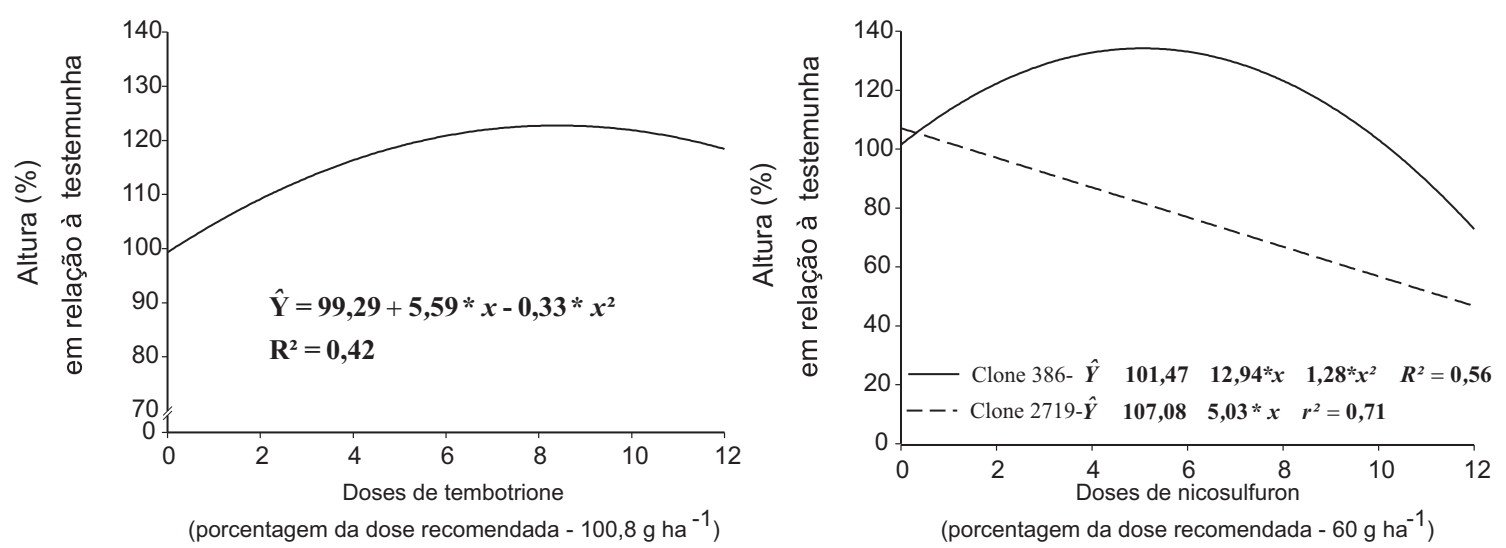

Figura 2 - Variação em altura de plantas de eucalipto (média de dois clones) submetidas à deriva simulada dos herbicidas tembotrione e nicossulfuron em diferentes doses.

Figure 2 - Variation in height of eucalyptus plants (average of two clones) submitted to simulated drift of the herbicides nicosulfuron and tembotrione at different doses.
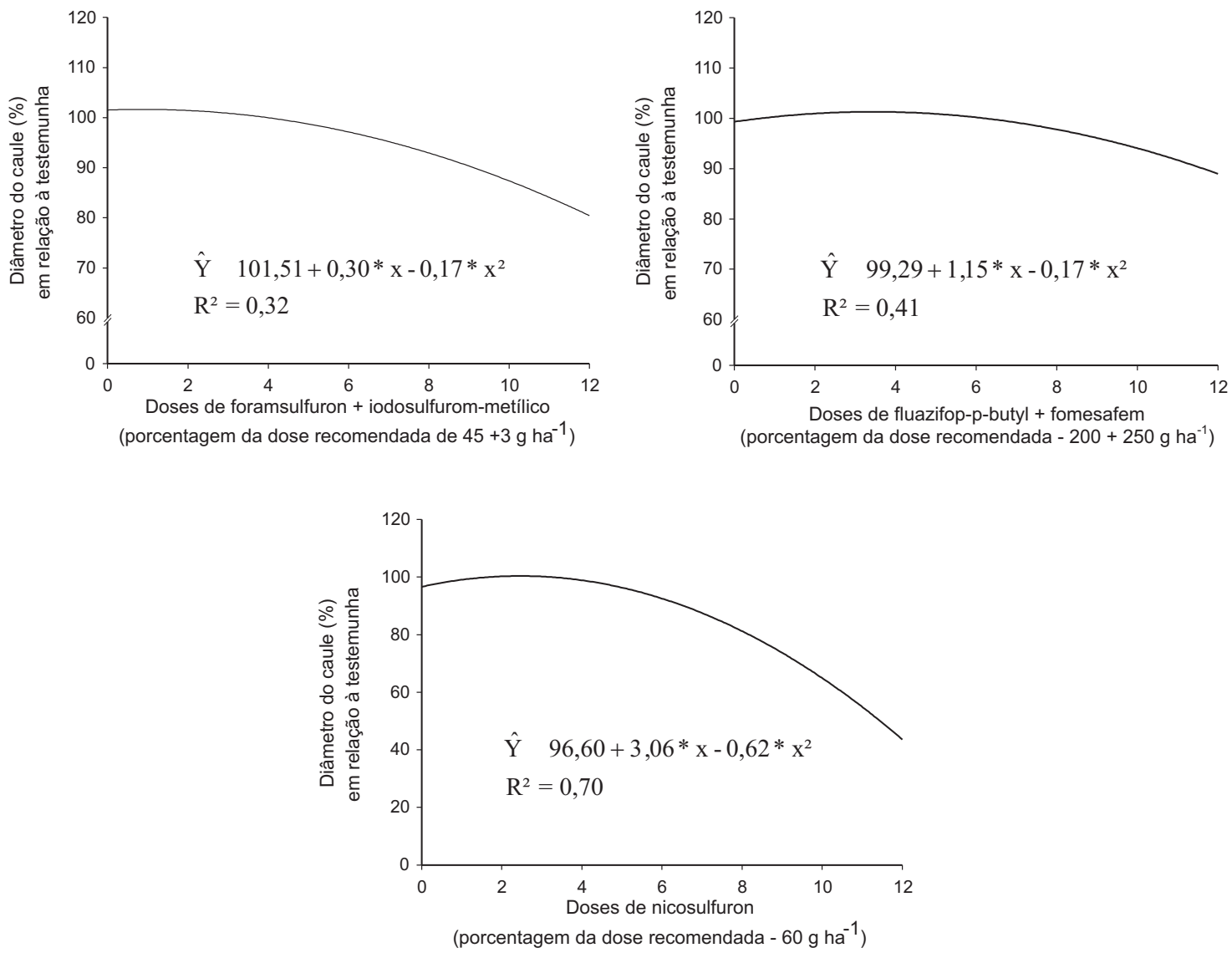

Figura 3 - Variação do diâmetro do caule de plantas de eucalipto (média de dois clones) submetidas à deriva simulada dos herbicidas foramsulfuron + iodosulfurom-metílico, fluazifop-p-butyl + fomesafen e nicossulfuron em diferentes doses.

Figure 3 - Variation of stem diameter of eucalyptus plants (average of two clones) submitted to simulated drift of the herbicides foramsulfuron iodosulfurom-methyl, fluazifop-p-butyl + fomesafen and nicosulfuron at different doses. 


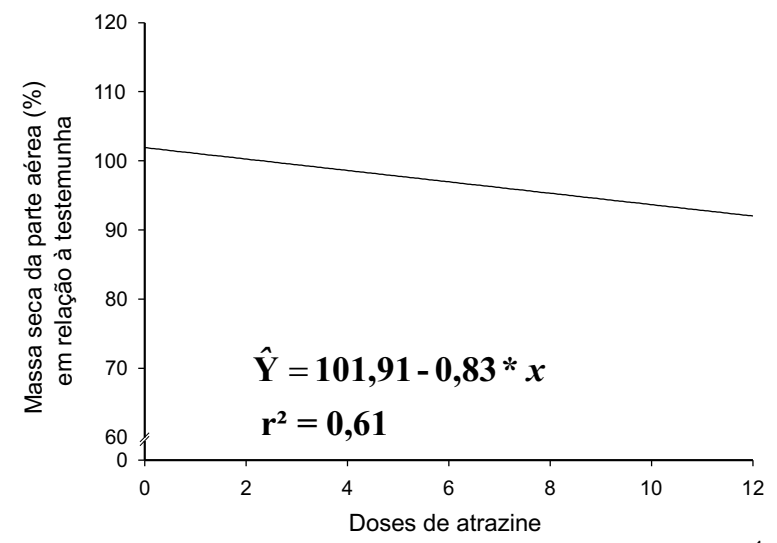

(porcentagem em relação a dose recomendada- $2,4 \mathrm{~kg} \mathrm{ha}^{-1}$ )

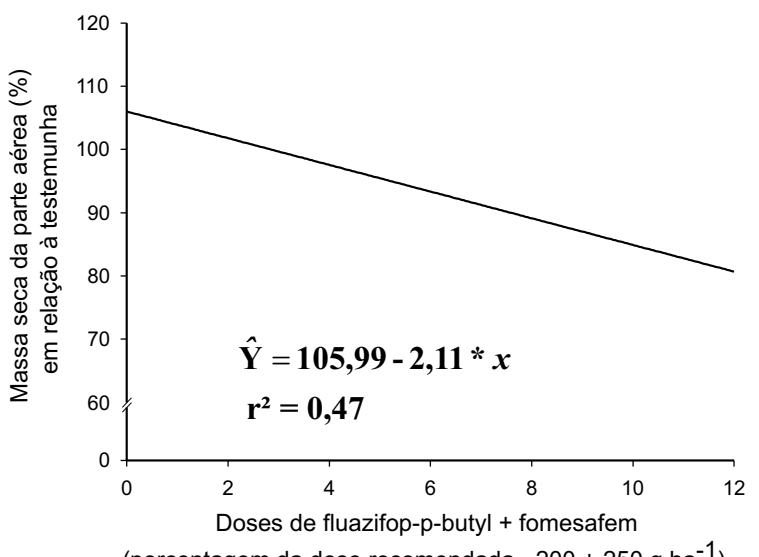

(porcentagem da dose recomendada $-200+250 \mathrm{~g} \mathrm{ha}^{-1}$ )
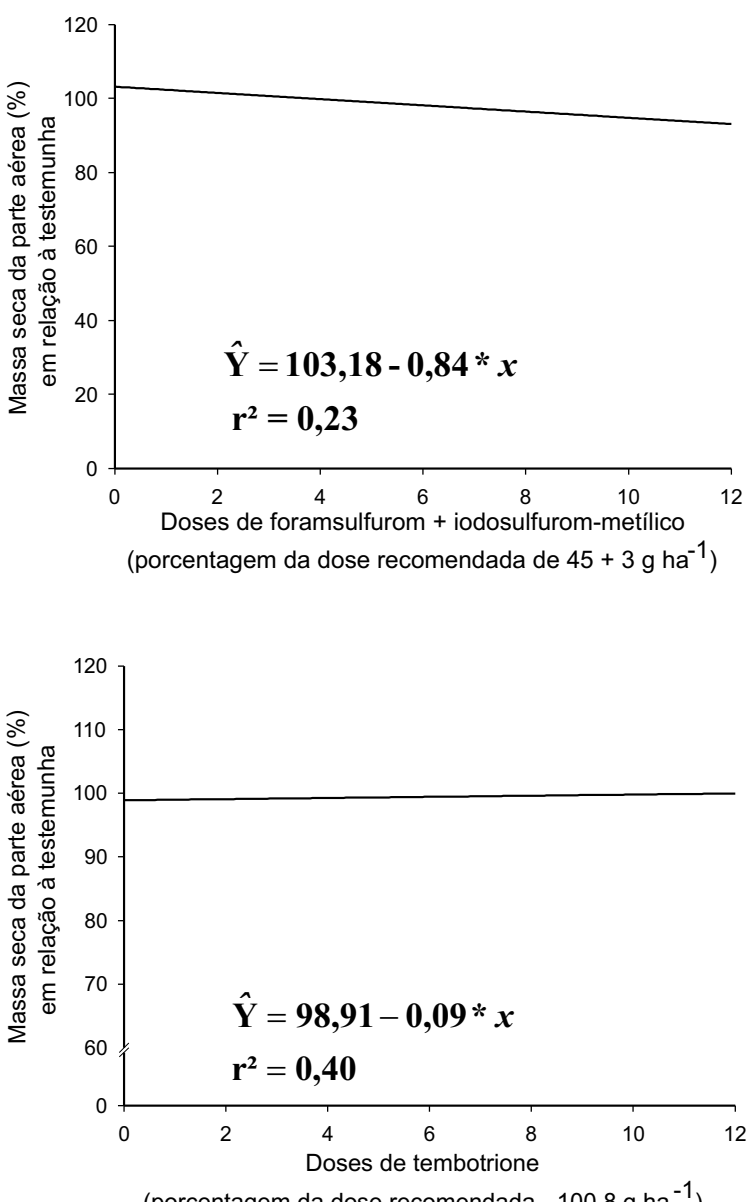

(porcentagem da dose recomendada $-100,8 \mathrm{~g} \mathrm{ha}^{-1}$ )

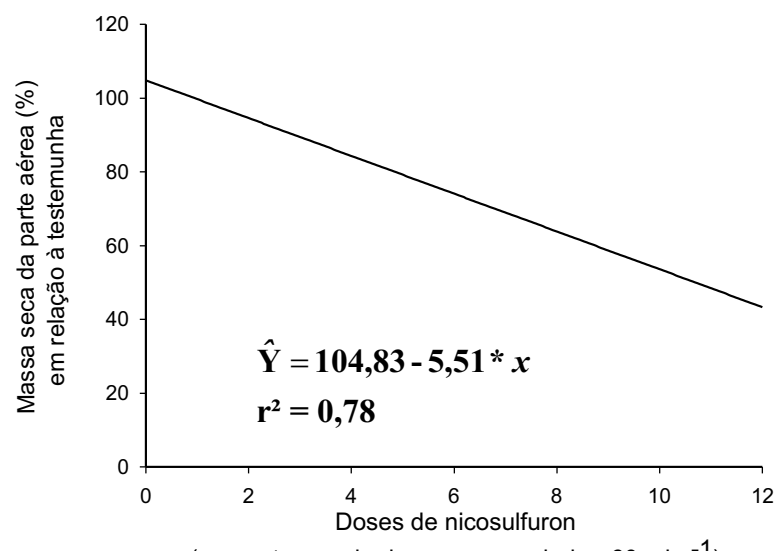

(porcentagem da dose recomendada - $60 \mathrm{~g} \mathrm{ha}^{-1}$ )

Figura 4 - Massa de matéria seca da parte aérea de plantas de eucalipto (média de dois clones) submetidas à deriva simulada dos herbicidas atrazine, foramsulfuron, iodosulfurom-metílico, fluazifop-p-butyl + fomesafen, tembotrione e nicossulfuron em diferentes doses.

Figure 4-Shoot dry mass of eucalyptus plants (average of two clones) submitted to simulated drift of the herbicides atrazine, foramsulfuron iodosulfurom-methyl, fluazifop-p-butyl + fomesafen, tembotrione and nicosulfuron at different doses.

Revista Árvore, Viçosa-MG, v.36, n.1, p.65-73, 2012 


\section{DISCUSSÃO}

As plantas tratadas com a mistura formulada de fluazifop-p-butyl + fomesafen apresentaram necroses até os 15 DAA, com intoxicação de até $66 \%$ na dose de $12 \%$, porém se verificaram sinais de recuperação das plantas aos 30 DAA, em todas as doses testadas. Ronchi e Silva (2004), estudando a tolerância de plantas de café ao fluazifop-p-butyl (200 g ha-1) + fomesafen (250 $\mathrm{g} \mathrm{ha}^{-1}$ ), observaram apenas leves injúrias nas folhas mais novas (inferiores a 20\%) sem prejudicar o crescimento em altura e diâmetro do caule até 70 dias após a aplicação. É importante ressaltar que o fomesafen é o responsável pelo efeito tóxico dessa mistura formulada, pois o fluazifop-p-butyl é tóxico apenas para monocotiledôneas.

As plantas tratadas com 3 e 6\% da dose recomendada de nicossulfuron tiveram intoxicação máxima aos 7 DAA iguais a 7,1 e 26,8\%, respectivamente, apresentando sinais de recuperação aos 30 DAA. Já os clones tratados com $12 \%$ da dose apresentaram elevado incremento da intoxicação entre os 15 e 30 DAA, chegando a $83 \%$ ao final desse período, não apresentando sinais de que haveria recuperação. Espécies tolerantes ao nicossulfuron metabolizam rapidamente esse herbicida, transformando-o em compostos não fitotóxicos (SPADER; RIBAS, 2001). Entretanto, pode-se apresentar sensibilidade diferencial, dependendo do estádio de desenvolvimento da planta, do ambiente e da dose (GUBBIGA et al., 1995).

A capacidade de recuperação das plantas de eucalipto tratadas com glyphosate é relatada por Tuffi Santos et al. (2007b). Trabalhando em condições de campo, esses autores observaram que as plantas de eucalipto que apresentaram intoxicação de até $20 \%$ não tiveram seu crescimento reduzido pelo herbicida. Entretanto, plantas com intoxicação nas faixas de 21-30, 31-40 e 41-50\% sofreram redução no volume de madeira, estimado aos 360 DAA, de 18, 26 e 48\%, respectivamente, em relação à testemunha. No caso do glyphosate, acredita-se que a diferença de sensibilidade entre genótipos de eucalipto seja atribuída a diferenças na absorção, translocação, compartimentalização, exsudação radicular e no metabolismo da molécula herbicida (TUFFI SANTOS et al., 2006a).

A variável altura de plantas foi afetada apenas pelo tembotrione e pelo nicossulfuron. A altura das plantas tratadas com tembotrione assumiu comportamento parabólico, apresentando-se, no entanto, até mesmo com $12 \%$ da dose recomendada, incremento em altura maior que o da testemunha. Assim, a ação do tembotrione, em todas as doses avaliadas, estimulou, em menor ou maior grau, o crescimento em altura. A altura das plantas tratadas com nicossulfuron variou, pois o clone 2719 sofreu decréscimo linear em função do aumento da dose, com redução de 54\% da altura na dose de 12\%, enquanto no clone 386 o comportamento foi parabólico, sendo observado nas plantas tratadas com $12 \%$ da dose crescimento em altura 28,1\% inferior ao da testemunha. Essa diferença entre clones, segundo Tuffi Santos et al. (2005), ocorreu porque, quanto menor a seletividade do material genético para o herbicida, menor o crescimento das plantas quando em contato com o herbicida.

O comportamento parabólico das variáveis pode ser explicado pelo fenômeno denominado "Hormesis”, que supõe que em doses muito baixas os herbicidas poderiam estar estimulando o crescimento das plantas de eucalipto. Erlich introduziu o termo "Hormesis" em 1943 para descrever o fenômeno no qual substâncias que são tóxicas em doses elevadas podem ser benéficas em doses baixas (CALABRESE, 2005). Cedergreen (2008), testando em cevada de 10 a 15 doses de oito herbicidas, observou que glyphosate e metsulfuronmethyl estimularam o incremento da biomassa em aproximadamente $25 \%$ quando aplicados em doses correspondentes a 5-10\% da recomendada. Duke et al. (2006) citaram exemplos de "Hormesis" proporcionados por vários herbicidas sobre o incremento em altura, massa de matéria seca e teor de proteína, entre outros, em culturas como soja, trigo, milho e centeio.

O herbicida que mais afetou o incremento em diâmetro do caule foi o nicossulfuron. As plantas tratadas com $12 \%$ da dose desse herbicida apresentaram-se 57\% menores que a testemunha, enquanto as tratadas com foramsulfuron + iodossulfurom-metílico e fluazifopp-butyl + fomesafen apresentaram plantas 10 e 12,1\% menores que a testemunha com essa mesma dose.

Entre os herbicidas testados, o fluazifop-p-butyl + fomesafen e o nicossulfuron foram os que mais limitaram o acúmulo de matéria seca da parte aérea, sendo as plantas 28,2 e $66,5 \%$ menores que a testemunha, respectivamente, na dose de $12 \%$ da recomendada.

Revista Árvore, Viçosa-MG, v.36, n.1, p.65-73, 2012 
Tuffi Santos et al. (2006b), estudando cinco espécies de eucalipto, observaram que os herbicidas glyphosate, triclopyr e carfentrazone-ethyl, nas doses de 3, 6 e $12 \%$ das recomendadas, afetaram a altura e a massa de matéria seca da parte aérea, não sendo verificada diferença no diâmetro do caule. Takahashi et al. (2009) observou redução na massa de matéria seca foliar de 4,6\% nos dois clones tratados com clomazone na dose de 180 g. ha- ${ }^{-1}$ (10\% da dose recomendada), em comparação com a testemunha.

Os herbicidas afetaram o crescimento das plantas de eucalipto, limitando, principalmente, o incremento em massa de matéria seca da parte aérea. O risco de perdas de produtividade, caso haja intoxicação via deriva, é menor com atrazine, foramsulfurom + iodossulfurom-metílico e tembotrione e maior com fluazifop-p-butyl + fomesafen e nicossulfuron.

Entre os produtos testados, o tembotrione é o que tem maior potencial para ser utilizado em áreas de eucalipto, podendo ser considerada a possibilidade de extensão de uso desse produto. Os demais herbicidas podem ser utilizados no manejo das plantas daninhas nas culturas consorciadas com o eucalipto, desde que sejam tomados cuidados para que não haja deriva desses insumos no eucalipto.

\section{REFERÊNCIAS}

ALVES, L. W. R. et al. Efeito da aplicação de subdoses dos herbicidas glyphosate e oxyfluorfen, simulando deriva sobre a cultura do milho (Zea mays L.). Ciência e Agrotecnologia, v.24, n.4, p.889-897, 2000.

ANDERSON, D. D. et al. Mechanism of primisulfuron resistance in a shattercane (Sorghum bicolor) biotype. Weed Science, v.46, n.1, p.158-162, 1998.

BODE, L. E. Downwind drift deposits by ground applications. In: PESTICIDE DRIFT

MANAGEMENT SYMPOSIUM, 1984, Brookings. Proceedings... Brookings: South Dakota State University, 1984. p.50.

CALABRESE, E. J. Historical blunders: how toxicology got the dose-response relationship half right. Cellular and Molecular Biology, v.51, p.643-654, 2005.

Revista Árvore, Viçosa-MG, v.36, n.1, p.65-73, 2012
CEDERGREEN, N. Herbicides can stimulate plant growth. Weed Research, v.48, p.429-438, 2008.

COSTA, A. G. F. et al. Períodos de interferência de trapoeraba (Commelina benghalensis Hort.) no crescimento inicial de eucalipto (E. grandis W. Hill ex Maiden). Revista Árvore, v.28, n. 4, p.471-478, 2004.

DUKE, S. O. et al. Hormesis: Is it an important factor in herbicide use and allelopathy? Outlooks on Pest Management, February, p.29-33, 2006.

FERREIRA, F. A.; SILVA, A. A.; FERREIRA, L. R. Mecanismos de ação de herbicidas In: CONGRESSO BRASILEIRO DE ALGODÃO, 5., 2005, Salvador. Anais... Salvador: 2005.

FRANS, R. E. Measuring plant responses. In: WILKINSON, R. E. (Ed.). Research methods in weed science. [S.l.]: Southern Weed Science Society, 1972. p.28-41.

GUBBIGA, N. G. et al. Effect of nicosulfuron on johnsongrass (Sorghum halepense) control and corn (Zea mays) performance. Weed

Technology, v.9, n.3, p.574-581, 1995.

MAGALHÃES, P. C. et al. Efeito de doses reduzidas de glyphosate e paraquat simulando deriva na cultura do milho. Planta Daninha, v.19, n.2, p.247-253, 2001.

PRESTON, C.; MALLORY-SMITH, C. A. Biochemical mechanisms, inheritance, and molecular genetics of herbicide resistance in weeds. In: STEPHEN, B. P.; DALE, L. S. Herbicide resistance and world grains. Boca Raton: CRC, 2001. p.34-76.

RONCHI, C. P.; SILVA, A. A. Weed control in young coffee plantations through post-emergence herbicide application on to total area. Planta Daninha, v.22, n.4, p.607-615, 2004.

SPADER,V.; RIBAS, R. A. Seletividade e dose de injúria econômica de nicosulfuron aplicado em diferentes estádios de desenvolvimento da cultura do milho. Ciência Rural, v.31, n.6, p.929-934, 2001. 
SOUZA, L. S. et al. Efeito alelopático de plantas daninhas e concentrações de capim braquiária (Brachiaria decumbens) no desenvolvimento inicial de eucalipto (E. grandis). Planta

Daninha, v.21, n.3, p.343-354, 2003.

TAKAHASHI, E. N. et al. Consequências da deriva do clomazone e sulfentrazone em clones de E. grandis x E. urophylla. Revista Árvore, v.33, n.4, p.675-683, 2009.

TILL, D. Lipid biosynthesis inhibitors. In: HERBICIDE action course. West Laffayette: Purdue University, 2003. p.293-347.

TUFFI SANTOS, L. D. et al. Crescimento e morfoanatomia foliar de eucalipto sob efeito de deriva do glyphosate. Planta Daninha, v.23, n.1, p.133-142, 2005.

TUFFI SANTOS, L. D. et al. Intoxicação de espécies de eucalipto submetidas a deriva de glyphosate. Planta Daninha, v.24, n.2, p.359-364, 2006a.

TUFFI SANTOS, L. D. et al. Intoxicação de eucalipto submetido à deriva simulada de diferentes herbicidas. Planta Daninha, v.24, n.3, p.521-526, 2006b.
TUFFI SANTOS, L. D. et al. Crescimento e concentração de nutrientes na parte aérea de eucalipto sob efeito da deriva do glyphosate. Cerne, v.13, n.4, p.347-352, 2007a.

TUFFI SANTOS, L. D. et al. Crescimento do eucalipto sobre efeito da deriva de glyphosate. Planta Daninha, v.25, n.1, p.133-137, 2007b.

TUFFI SANTOS, L.D. et al. Leaf anatomy and morphometry in three eucalypt clones treated with glyphosate. Brazilian Journal of Biology, v.69, n.1, p.129-136, 2009.

VALVERDE, S. R. O comportamento do mercado da madeira de Eucalipto no Brasil. Biomassa \& Energia, v.1, n.4, p.393-403, 2004.

YAMASHITA, O. M. et al. Resposta de varjão (Parkia multijuga) a subdoses de glyphosate. Planta Daninha, v.24, n.3, p.527-531, 2006.

WEED SCIENCE. Glycines resistant weeds by species and country Disponível em: <http:// wwwweedscience.org > . Acesso em: 13 abr. de 2010. 